\title{
Carotid intima-media thickness and endothelial function: useful surrogate markers for establishing cardiovascular risk in patients with inflammatory rheumatic disease - authors' response
}

\author{
Jet JCS Veldhuijzen van Zanten ${ }^{1,2}$ and George D Kitas ${ }^{1,2}$ \\ ${ }^{1}$ School of Sport and Exercise Sciences, University of Birmingham, Birmingham, B15 2TT, UK
2 Department of Rheumatology, Dudley Group of Hospitals NHS Trust, Pensnett Road, Dudley, DY1 2HQ, UK
}

Corresponding author: George D Kitas, GD.Kitas@dgoh.nhs.uk

Published: 16 May 2008

Arthritis Research \& Therapy 2008, 10:404 (doi:10.1186/ar2410)

This article is online at http://arthritis-research.com/content/10/3/404

(C) 2008 BioMed Central Ltd

See related editorial by Veldhuijzen van Zanten and Kitas, http://arthritis-research.com/content/10/1/102

and related letter by Gonzalez-Gay et al., http://arthritis-research.com/content/10/3/403

We thank Gonzalez-Juanatey and colleagues [1] for their response to our editorial [2]. They refer to their interesting recent work [3], reporting that carotid intima-media thickness (IMT) is associated with future cardiovascular events in patients with rheumatoid arthritis (RA). Although this is potentially important, because this was a longitudinal observational study conducted over a 5-year period of follow up, there are some shortcomings that may be of significance. The cohort (47 patients) and number of events (8) were small, allowing for statistical error. Patients who developed cardiovascular events not only had significantly higher carotid IMT but were also significantly older than those who did not; greater age is associated with both carotid IMT and cardiovascular event risk [4]. This, together with other possible confounders, might have had a major impact on the results. The degree of systemic inflammation in patients when carotid IMT was assessed and during follow up was not presented. One of those patients who developed a cardiovascular event appears to have been an extreme outlier with a very high carotid IMT. Did that patient have a particularly high inflammatory load at the time of assessment?

Carotid IMT has been shown to reduce in response to antitumour necrosis factor- $\alpha$ treatment in patients with RA [5]. This raises the question as to whether, in states characterized by high-grade inflammation such as RA, carotid IMT reflects current inflammatory load rather than more permanent, structural vessel changes. If the former is true, then a 'high' carotid IMT measured during a 'flare' of disease activity may not be a good predictor of future cardiovascular events. This question has not been addressed in the study conducted by
Gonzalez-Juanatey and colleagues [3]. Their study lends credence to the continuing use of surrogates of atherosclerotic cardiovascular disease in patients with RA. However, we believe that the short-term and long-term interplay between degrees of systemic inflammation and surrogates that are thought to reflect functional or structural vessel changes, as well as the overall metabolic state of the individual patient, requires more investigation in longitudinal studies designed specifically for this purpose.

\section{Competing interests}

The authors declare that they have no competing interests.

\section{References}

1. Gonzalez-Gay MA, Gonzalez-Juanatey C, Vazquez-Rodriguez TR, Martin J, Llorca J: Carotid intima-media thickness and endothelial function: useful surrogate markers for establishing cardiovascular risk in patients with inflammatory rheumatic disease. Arthritis Res Ther 2008, 10:403.

2. Veldhuijzen van Zanten JJCS, Kitas GD: Inflammation, carotid intima-media thickness and atherosclerosis in rheumatoid arthritis. Arthritis Res Ther 2008, 10:102.

3. Gonzalez-Juanatey C, Llorca J, Martin J Gonzalez-Gay MA: Carotid intima-media thickness predicts the development of cardiovascular events in patients with rheumatoid arthritis. Semin Arthritis Rheum 2008 [Epub ahead of print].

4. Lakatta EG, Levy D: Arterial and cardiac ageing: major shareholders in cardiovascular disease enterprises. Part 1: ageing arteries: a 'set up' for vascular disease. Circulation 2003, 107: 139-146.

5. Del Porto F, Laganá B, Lai S, Nofroni I, Tinti F, Vitale M, Podestà E. Mitterhofer AP, D'Amelio R: Response to anti-tumour necrosis factor alpha blockade is associated with reduction of carotid intima-media thickness in patients with active rheumatoid arthritis. Rheumatology 2007, 43:1111-1115. 